\title{
Three projects to emphasize the design in lens design
}

\section{Paul Leisher, Robert Bunch}

Paul O. Leisher, Robert M. Bunch, "Three projects to emphasize the design in lens design," Proc. SPIE 9793, Education and Training in Optics and

Photonics: ETOP 2015, 97930P (8 October 2015); doi: 10.1117/12.2223081

SPIE Event: Education and Training in Optics and Photonics: ETOP 2015, 2015, Bordeaux, France 


\title{
Three projects to emphasize the "design" in lens design
}

\author{
Paul O. Leisher* and Robert M. Bunch \\ Rose-Hulman Institute of Technology, 5500 Wabash Ave., Terre Haute, IN, USA 47803
}

\begin{abstract}
Lens design is a cornerstone of optical engineering education. At Rose-Hulman Institute of Technology, our implementation begins with a review of paraxial optics and system layout before moving into a theoretical treatment of monochromatic and chromatic aberration theory and image quality; small design problems presented along the way provide context and exposure to lens design software (Code V and Zemax). At the undergraduate level, pedagogical methods which focus on open-ended design/synthesis are especially important as these skills are still developing in students. To this end, a series of three design projects were recently introduced. The first project is the design of a fast photographic zoom lens. Constraints are provided for sensor format, overall length, allowable glasses, maximum number of elements, maximum distortion, and the required image quality. In the second design project, students are tasked with the design of a reflective spectrometer system utilizing off-the-shelf optics from a provided list. Design specifications are placed on the wavelength span, resolution bandwidth, input format, and module footprint. The third design project places students in the position of selecting the best design for manufacture based on the results of an inverse sensitivity analysis and Monte Carlo tolerance analysis. The results are weighed against the expected manufacturing cost. This paper details the implementation of these projects, including lessons learned, assessment methodology, and student outcomes. Anecdotally, students who successfully complete all three projects demonstrate deeper understanding of lens design and several specific topics (optimization, multiconfiguration systems, coordinate breaks, diffractive optics, and tolerancing).
\end{abstract}

Keywords: Lens design, optical system design, optical engineering, education, ABET

\section{INTRODUCTION}

Optical lens design is the process of developing a lens system subject to given constraints, in order to meet certain performance requirements [1-5]. Most lens design courses focus on exact ray tracing, third- (and higher-) order aberration theory, image quality, and design of lens systems for reduced aberrations (typically with a strong emphasis on computer-aided design). These courses will often approach these subjects through a development of classical lens system designs such as the Chevalier, periscopic, Cooke triplet, Petzval, rapid rectilinear, and double Gauss lens. This approach to teaching lens design is logical in the sense that the design of lenses with increasing complexity directly supports mastery of the underlying theory. In most cases, the design experiences consists of the development of customized lens prescriptions to meet performance objectives.

While lens design courses have been implemented at both undergraduate and graduate levels, most schools offer the course at the graduate level only. At Rose-Hulman Institute of Technology (RHIT), lens design has been taught as a senior-level course for more than a decade as part of our ABET-accredited Bachelor of Science - Optical Engineering $(\mathrm{OE})$ undergraduate degree program. As part of our continuous improvement cycle, feedback from program stakeholders indicated that the course could be improved by including topics beyond imaging systems, including fiber couplers, laser optics, spectrometers and optical spectrum analyzers, general laboratory systems based on commercialoff-the-shelf components, and design for manufacturability. This feedback is consistent with the observation that our graduating students are placed into a wide variety of positions in both graduate programs and industry. While most of our graduates will never need to develop a custom lens prescription for a camera, microscope, etc., almost all will continue on in the field of optics and need to design an optical system to meet a set of requirements. As a result, the RHIT OE curriculum committee revised the course, renaming it "OE 480 - Optical System Design" and placing a new emphasis on the design of general optical systems.

*pleisher@ieee.org

Education and Training in Optics and Photonics: ETOP 2015, edited by Eric Cormier, Laurent Sarger Proc. of SPIE Vol. 9793, 97930P · @ 2015 SPIE, IEEE, OSA, ICO · doi: 10.1117/12.2223081 
OE 480 is a 4 credit (meeting 4 times a week over a 10 week academic quarter) lecture-based course which is taken by Senior-level undergraduates. It is also offered as a 500-level graduate course as part of our Master of Science OE program). The course has one prerequisite, OE 280 - Geometrical Optics, in which students learn the fundamentals of paraxial optics, ray tracing, and aberrations. The course description is shown below:

OE 480 Optical System Design - Review of geometrical optics and exact ray tracing. Chromatic and monochromatic aberrations. Image quality assessment, spot size, point spread function, Strehl ratio, and modulation transfer function. Classical lens design and design of various imaging, nonimaging, and diffractive optical systems. First-order layout, computer-based optimization, tolerancing, and manufacturing considerations.

The course is divided into two halves; during the first five weeks, we review geometrical optics, introduce computerbased optimization software (Code V and Zemax - the students can select either software package to work in), and cover chromatic and monochromatic aberration theory in detail. Four homework assignments (mostly analytical but also containing a few classical lens design problems) support the lectures and two exams are given, one each in the second and fifth week of class. Beginning in the sixth week, the students begin work on the first of three design projects. Significant time is allocated for the students to work on their projects in-class; a handful of lectures provide just-in-time coverage of topics relevant to the work the students are doing on each project. For example, during the spectrometer design project, two lectures on coordinate breaks (decenters) and one lecture on diffraction gratings in Code V / Zemax are given; an additional three lecture periods are set aside for the students to work on their spectrometer in-class (giving the students ample opportunity to ask specific questions as they arise). Performance on the design projects amounts to about $50 \%$ of the total grade in the course.

Student performance on each of the design projects is assessed in one-on-one oral design reviews. Each students is required to prepare a short presentation to walk through the development of their solution with the instructor. Fifteen minutes are allotted to each student. This approach was selected for several reasons. First, by requiring an oral defense of each of their designs, each student is held individually accountable for proving that they understand their design in details. Second, the approach closely simulates (and further prepare them for) the design review process that the students are likely to encounter in industry (product designs are rarely make it through development without multiple design review meetings). Finally, for students who are unable to complete the project successfully, the approach allows the instructor to ask probing follow-up questions to help determine exactly the degree to which the student falls short. Grading rubrics are used to ensure key questions and concepts are evaluated consistently and to provide the students with a detailed understanding the letter grade they receive on each project.

The three projects from the 2014-15 academic year were as follows: 1) design of a refractive photographic zoom lens, 2) design of a reflectance grating spectrometer / monochromatic, and 3) manufacturability analysis of three contemporary lens systems using the tolerance grade mapping approach [6]. Each of these is discussed in further detail below.

\section{DESIGN PROJECT 1 - PHOTOGRAPHIC ZOOM LENS}

This project covers the design of a photographic zoom lens and represents a classic lens design problem - the students are tasked with developing the fastest (lowest F/\#) custom prescription lens system that they can which meets certain constraints including field of view, effective focal length, image quality, distortion, and track length. Students are expected to select an appropriate lens form and perform the necessary calculations by hand to develop a reasonable initial design; optimization is performed in Code $\mathrm{V}$ or Zemax. The image quality requirement is specified as a minimum modulation transfer function (MTF) value at a certain spatial frequency. Subjective constraints are also included (noting image quality at $100 \mathrm{~mm}$ EFL is more important than at other zoom positions).

Figure 1 depicts the project assignment which contains the objective and design constraints. Technical considerations are provided to help the students through the design process and assist them in their preparation for the oral design review. There are several expectations which are set, but not explicitly called out for in the assignment. For example, the lens is expected to be well corrected for chromatic aberrations over the wavelength range sensed by a Si CMOS detector array in typical ambient lighting conditions. This requires proper selection of multiple wavelengths, and each should be weighted appropriately. 


\section{Project 1 - Photographic Zoom Lens}

You have been tasked with designing a photographic zoom lens.

Design constraints:

- The Si CMOS detector is $6.66 \mathrm{~mm} \times 5.32 \mathrm{~mm}$ with a resolution of $1280 \times 1024$ pixels.

- The overall lens length (including image distance) must be below $200 \mathrm{~mm}$.

- $\quad$ The design may use no more than three different glass types.

- $\quad$ The lens must contain no more than four elements and a stop.

- Up to two elements may be cemented doublets (six different glass elements total).

- $\quad$ The lens must be zoomable with effective focal length variable from $50 \mathrm{~mm}$ to $100 \mathrm{~mm}$.

- $\quad$ The zoom function must function by translating lens elements or groups.

- $\quad$ No more than three elements may shift (two spacings + defocus)

- $\quad$ The stop diameter and F/\# are allowed to vary with zoom.

- $\quad$ Distortion must be kept below $1 \%$.

- $\quad$ The desired image quality over the full field of view and all zoom settings is MTF > 0.4 at 30 cycles $/ \mathrm{mm}$, however the image quality for the $100 \mathrm{~mm}$ EFL setting is somewhat more important.

You should seek to design the fastest lens (at all zoom positions) such that the image quality is sufficiently good.

Technical considerations / questions to be ready for...

- What approach did you take to the design? Did you start from a known good design and scale from there? What pre-design work did you do?

- How were the technical requirements translated into constraints in CodeV?

- How did your system account for the spectral response of the Si photodetector?

- What have you done to ensure the lens can actually be made and mounted?

- How do the mechanical requirements (spacing, apertures), image quality, and lens speed vary as the systems is zoomed?

- What would a photograph taken with your lens look like at various focal length settings?

- How much better could your system have been if one of these requirements were relaxed? For example, if you were allowed to use a single asphere, another element, or an additional translation in the zoom housing, how much faster could the lens have been made?

- It is important to note the image quality requirement may not actually be achievable. You should be prepared to explain this and propose an alternate set of design constraints which would enable the image quality to exceed the specification.

Figure 1. Photographic zoom lens project assignment. Design constraints and technical considerations are provided.

An example student design is depicted in Figure 2. This student provided a table comparing the project constraints (requirements) and the results from their design. The field of view was set along the diagonal of the detector with maximum field point at the corner of the detector array. The system was based on a telephoto zoom lens and optimized using Code V. This particular student met all of the design requirements, and their design comprised two single elements, two doublets and an aperture serving as the system stop. This design represented the fastest among all in-spec submissions received ( $\mathrm{F} / 2.8$, typical designs were in the $\mathrm{F} / 4$ to $\mathrm{F} / 8$ range). 


\begin{tabular}{|c|c|c|c|}
\hline & \multicolumn{2}{|r|}{ Requirements } & Achievements \\
\hline Detector size & \multicolumn{2}{|c|}{$6.66 \mathrm{~mm} \times 5.32 \mathrm{~mm}$} & $\mathrm{R}=4.262 \mathrm{~mm}$ \\
\hline Number of elements & \multicolumn{2}{|c|}{$\begin{array}{l}\text { Four elements (two doublets are } \\
\text { allowed) }+ \text { stop }\end{array}$} & $\begin{array}{l}\text { Two single elements } \\
+ \text { two doublets }+ \text { stop }\end{array}$ \\
\hline Lens & \multicolumn{2}{|c|}{ No more than three types } & Two types \\
\hline \multirow{3}{*}{$\begin{array}{c}\text { EEL (zoom) } \\
\& \\
\text { overall length }\end{array}$} & $50 \mathrm{~mm}$ & \multirow{3}{*}{$\begin{array}{l}\text { With less than } 200 \mathrm{~mm} \\
\text { overall length }\end{array}$} & $50 \mathrm{~mm}$ with $100.3 \mathrm{~mm}$ \\
\hline & $75 \mathrm{~mm}$ & & $75 \mathrm{~mm}$ with $169.49 \mathrm{~mm}$ \\
\hline & $100 \mathrm{~mm}$ & & $100 \mathrm{~mm}$ with $198.69 \mathrm{~mm}$ \\
\hline Shifting & \multicolumn{2}{|c|}{ Two spacings + defocus } & Two spacings \\
\hline $\mathbf{F} / \#$ & & $\begin{array}{l}\text { Minimizing } \\
\text { than } \mathrm{f} / 34.0389) \\
\end{array}$ & $\begin{array}{l}\text { Constant } \mathrm{f} / 2.8 \\
\text { for full range }\end{array}$ \\
\hline \multirow{3}{*}{ MTF } & \multirow{3}{*}{\multicolumn{2}{|c|}{$\begin{array}{l}\text { More than } 0.4 \text { at } 30 \text { cycles } / \mathrm{mm} \\
\text { for the range of EFL }\end{array}$}} & About 0.42 for $50 \mathrm{~mm} \mathrm{EFL}$ \\
\hline & & & About 0.66 for $75 \mathrm{~mm}$ EFL \\
\hline & & & About 0.56 for $100 \mathrm{~mm} \mathrm{EFL}$ \\
\hline \multirow{3}{*}{ Distortion } & \multirow{3}{*}{\multicolumn{2}{|c|}{ Less than $1 \%$}} & About $-0.7 \%$ for $50 \mathrm{~mm} \mathrm{EFL}$ \\
\hline & & & About $-0.3 \%$ for $75 \mathrm{~mm}$ EFL \\
\hline & & & About $+0.2 \%$ for $100 \mathrm{~mm} \mathrm{EFL}$ \\
\hline
\end{tabular}

\begin{tabular}{|c|c|}
\hline Wavelength & From $420 \mathrm{~nm}$ to $660 \mathrm{~nm}$ \\
\hline $\begin{array}{c}\text { Lens groups- } \\
\text { elements }\end{array}$ & $\begin{array}{c}\text { 4 groups composed of } 6 \text { elements } \\
\text { (2 groups are doublets) }\end{array}$ \\
\hline Glass & $\begin{array}{c}\text { 2 types of lenses } \\
\text { (NLAF7_SCHOTT and } \\
\text { NFK5_SCHOTT) }\end{array}$ \\
\hline Filter diameter & $39 \mathrm{~mm}$ \\
\hline Lens type & Telephoto zoom lens \\
\hline Focal length & From 50 to $100 \mathrm{~mm}$ \\
\hline Aperture & Constant $\mathrm{f} / 2.8$ \\
\hline Aperture blade & Circular aperture \\
\hline FOV & From 4.87 to 2.44 for $540 \mathrm{~nm}$ \\
\hline Weight (only lenses) & $61.84 \mathrm{~g}$ \\
\hline $\begin{array}{c}\text { Dimensions } \\
\text { (approx.) }\end{array}$ & $\begin{array}{c}\text { Length: from } 100 \mathrm{~mm} \text { to } 200 \mathrm{~mm} \\
\text { Diameter: } 45 \mathrm{~mm}\end{array}$ \\
\hline
\end{tabular}

\begin{tabular}{|c|c|c|c|c|c|c|c|c|}
\hline \multicolumn{7}{|c|}{ W. Lens Data Manager } & \multicolumn{2}{|c|}{\begin{tabular}{|l|l}
0 & 03 \\
\end{tabular}} \\
\hline \multicolumn{3}{|c|}{ Surface Properties.. } & \multirow[b]{2}{*}{ Y Radius } & \multirow[b]{2}{*}{ Thickness } & \multirow[b]{2}{*}{ Glass } & \multirow[b]{2}{*}{$\begin{array}{l}\text { Refract } \\
\text { Mode }\end{array}$} & \multirow[b]{2}{*}{$\begin{array}{c}\mathrm{Y} \\
\text { Semi-Aperture }\end{array}$} & \multirow[b]{2}{*}{ 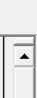 } \\
\hline Surface \# & $\begin{array}{l}\text { Surface } \\
\text { Name }\end{array}$ & $\begin{array}{l}\text { Surface } \\
\text { Type }\end{array}$ & & & & & & \\
\hline Object & & Sphere & Infinity & Infinity & & Refract & 0 & \\
\hline 1 & & Sphere & $86.9659 \mathrm{~V}$ & $19.0000 \mathrm{~V}$ & NLAF7_SC & Refract & $19.5000^{\circ}$ & \\
\hline 2 & & Sphere & $50.0371 \mathrm{~V}$ & 0.0000 & & Refract & $19.5000^{\circ}$ & \\
\hline 3 & & Sphere & 50.0371 & $4.1941 \mathrm{~V}$ & NFK5_SCH & Refract & $19.5000^{\circ}$ & \\
\hline 4 & & Sphere & $-482.3158 \mathrm{~V}$ & $15.6840 \mathrm{~V}$ & & Refract & $19.5000^{\circ}$ & \\
\hline Stop & & Sphere & Infinity & $120.0000^{2}$ & & Refract & $14.6603^{\circ}$ & \\
\hline 6 & & Sphere & $33.2907 \mathrm{~V}$ & $18.2462 \mathrm{~V}$ & NFK5_SCH & Refract & $11.4143^{\circ}$ & \\
\hline 7 & & Sphere & $-31.8204 \mathrm{~V}$ & 0.0000 & & Refract & $9.7264^{\circ}$ & \\
\hline 8 & & Sphere & -31.8204 & $11.7264 \mathrm{v}$ & NLAF7_SC & Refract & $9.7264^{\circ}$ & \\
\hline 9 & & Sphere & $-95.5137 \mathrm{~V}$ & $1.0000^{2}$ & & Refract & $9.1277^{\circ}$ & \\
\hline 10 & & Sphere & $16.8553 \mathrm{~V}$ & $3.1319 \mathrm{~V}$ & NFK5_SCH & Refract & $7.2328^{\circ}$ & \\
\hline 11 & & Sphere & $-44.3666 \mathrm{~V}$ & $3.7992 \mathrm{~V}$ & & Refract & $6.9721^{\circ}$ & \\
\hline 12 & & Sphere & $-25.5434 \mathrm{~V}$ & $1.4141 \mathrm{~V}$ & NLAF7_SC & Refract & $4.8232^{\circ}$ & \\
\hline 13 & & Sphere & $19.7627 \mathrm{~V}$ & $0.4950 \mathrm{~V}$ & & Refract & $4.3846^{\circ}$ & \\
\hline 14 & & Sphere & Infinity & 1.0000 & & Refract & $4.3843^{\circ}$ & \\
\hline Image & & Sphere & Infinity & 0.0071 & & Refract & $4.2715^{\circ}$ & \\
\hline \multicolumn{8}{|c|}{ End of Data } & 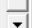 \\
\hline | 1 & & & & & & & & \\
\hline
\end{tabular}

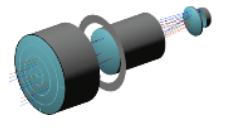

At $50 \mathrm{~mm}$ EFL

Figure 2. Example of one student submission. (Top Left) Table listing a comparison of design requirements and system performance (Top Right) Lens design information. (Bottom Left) Lens prescription at $100 \mathrm{~mm}$ EFL. (Bottom Right) 3D lens system layout at 50, 75, and $100 \mathrm{~mm}$ EFL.

\section{DESIGN PROJECT 2 - SPECTROMETER USING COTS COMPONENTS}

The goal of the second project is to design a grating based spectrometer / monochromator using off-the-shelf components. This project is representative of the kind of design work which takes place in a general optics research laboratory. Figure 3 depicts the project assignment which contains the objective and design constraints. A list of allowable commercial components from which the spectrometer can be designed is provided, and students are not allowed to change the prescription of any component. The system must be demonstrated (in software) to meet the both a minimum wavelength range and minimum resolution bandwidth in the presence of all optical effect, including diffraction and aberrations. The design must utilize reflecting components and fit within a given footprint, which makes the use of coordinate breaks (decenters) necessary for success. The students are free to select a detection scheme - for example, some students utilized fixed optics and the linear CCD detector array while others elected to use a scanning Galvo and single-point detector. This project serves as an excellent introduction to handling diffractive elements and coordinate breaks (decenters) within the Code V and Zemax design software. 


\section{Project 2 - Grating Spectrometer / Spectrum Analyzer Using COTS Components}

You have been tasked with designing a spectrometer using parts available from Thorlabs. For signal detection, you can use either a scanning galvo mirror + single element photodector or a linear detector array.

Design constraints:

- $\quad$ Allowable components (datasheets and pricing available on Thorlabs.com)

- Protected Silver Mirror - Off-Axis Parabolic - RFL 1" and 2" - Ø1/2" and Ø1"

- Protected Silver Mirror - Flat - Ø1/2", Ø1", Ø2", and Ø3"

- Protected Silver Mirror - Concave Spherical - EFL 12.0mm, 25.0mm, 50.0mm, 75.0mm, $100.0 \mathrm{~mm}, 150.0 \mathrm{~mm}, 200.0 \mathrm{~mm}$, and $500.0 \mathrm{~mm}-\varnothing 1 / 2 ", \varnothing 1 ", \varnothing 2 "$, and $\varnothing 75 \mathrm{~mm}$

- Protected Silver Mirror - Concave Cylindrical - EFL 25.0mm, 50.0mm, 100.0mm, 200.0mm, and $400.0 \mathrm{~mm}-\varnothing 1 "$

- $\quad$ Fixed Vertical Slit - Height 3 mm - Width $5 \mu \mathrm{m}, 10 \mu \mathrm{m}, 15 \mu \mathrm{m}, 20 \mu \mathrm{m}, 30 \mu \mathrm{m}, 40 \mu \mathrm{m}, 50 \mu \mathrm{m}$, $100 \mu \mathrm{m}, 150 \mu \mathrm{m}$, and $200 \mu \mathrm{m}$.

- $\quad$ Mounted Pinhole - Ø5 $\mu \mathrm{m}, \varnothing 10 \mu \mathrm{m}, \varnothing 15 \mu \mathrm{m}, \varnothing 20 \mu \mathrm{m}, \varnothing 25 \mu \mathrm{m}, \varnothing 30 \mu \mathrm{m}, \varnothing 50 \mu \mathrm{m}, \varnothing 75 \mu \mathrm{m}$, $\varnothing 100 \mu \mathrm{m}, \varnothing 150 \mu \mathrm{m}$.

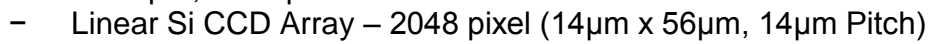

- $\quad$ Protected Silver Single-Axis Scanning Galvo Mirror - (10 mm max beam diameter, $\pm 20^{\circ}$ scan)

- Si Transimpedance Amplified Photodetector - $3.6 \mathrm{~mm}$ x $3.6 \mathrm{~mm}$ detector size

- Reflective Diffraction Grating - 300/mm ( $8^{\circ} 36^{\prime}$ blaze), 600/mm (17 $27^{\prime}$ blaze), and 1200/mm $\left(36^{\circ} 52^{\prime}\right.$ blaze).

- Wavelength span: 950 to $1050 \mathrm{~nm}$

- Resolution bandwidth: $0.5 \mathrm{~nm}$

- $\quad$ Fiber input: $\varnothing 200 \mu \mathrm{m}, 0.2 \mathrm{NA}$

- Footprint: less than $50 \mathrm{~cm} \times 50 \mathrm{~cm}$

Hints:

- You do not need to use all of the light from the fiber (spatial filtering is allowed).

- You can use flat mirrors to increase the optical path within the footprint limitation.

- $\quad$ Off-axis parabolic mirrors are an excellent on-axis collimators but require a small point source. They make relatively poor imaging mirrors at large field angles.

Technical considerations / questions to be ready for...

- What is the estimated cost to build your system (optics only, mounting hardware is free)?

- What is the spectral bandwidth of your system?

- What advantages/disadvantages does your design have over the other approach? (For example, what advantages does the galvo mirror design have over the detector array approach?)

- How would your system change if the wavelength span were changed to 750 to $850 \mathrm{~nm}$ ?

- How would you go about calibrating the wavelength in your system?

Figure 3. Grating spectrometer / spectrum analyzer using commercial off-the-shelf components project assignment. Design constraints (including a list of allowable components), hints, and technical considerations are provided.

Highlights from an example student submission are shown in Figure 4. The student included a table comparing the performance of their design to the minimum requirements. This particular student was able to achieve a resolution $2 \mathrm{X}$ better than the requirement, over a broader wavelength range and in a much smaller footprint. Their design utilizes a 10 $\mu \mathrm{m}$ input slit and $5 \mu \mathrm{m}$ exit slit and captures up to $0.065 \mathrm{NA}$ on the entrance side. This student demonstrated that the resolving capability of the system by tracing rays from the center and edge of the entrance slit, at multiple wavelengths, through the system and showing that no overlap occurs at the $10 \mu \mathrm{m}$ exit slit of the system. The design features an offaxis parabolic mirror which serves to collimate the light from the entrance slight, a $10 \mathrm{~mm}$ diameter Galvo mirror which scans the incidence angle on a 1200/mm diffraction grating. A second off-axis parabolic mirror focuses the light at the exit slit of the system. 


\begin{tabular}{|c|c|c|c|c|}
\hline & Requirements & Achievements & & \\
\hline Wavelength & $\begin{array}{l}\text { From } 950 \mathrm{~nm} \text { to } \\
1050 \mathrm{~nm}\end{array}$ & $\begin{array}{l}\text { From } 890 \mathrm{~nm} \text { to } \\
\quad 1110 \mathrm{~nm}\end{array}$ & \multirow{4}{*}{\multicolumn{2}{|c|}{$1000 \mathrm{~nm}$ and $1000.25 \mathrm{~nm}$}} \\
\hline Resolution & $0.5 \mathrm{~nm}$ & $0.25 \mathrm{~nm}$ & & \\
\hline Footprint & $\begin{array}{l}\text { Less than } 50 \mathrm{~cm} \mathrm{x} \\
50 \mathrm{~cm}\end{array}$ & $\begin{array}{c}7.5 \mathrm{~cm} \mathrm{x} \\
8.5 \mathrm{~cm}\end{array}$ & & \\
\hline $\begin{array}{l}\text { Numerical } \\
\text { aperture }\end{array}$ & - & $0.065 \mathrm{NA}$ & & \\
\hline Object height & - & $10 \mu \mathrm{m}$ & . & RMS $=$ \\
\hline Output slit size & & $5 \mu \mathrm{m}$ & - & \\
\hline
\end{tabular}

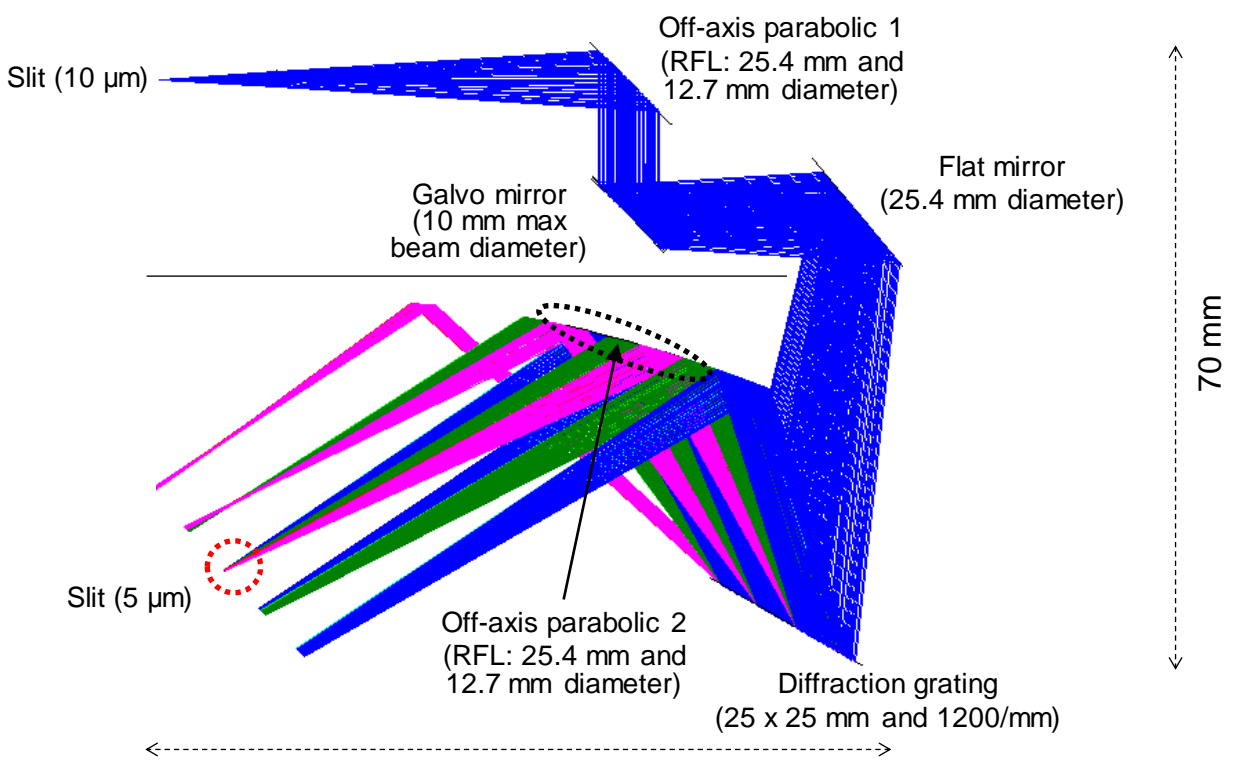

$85 \mathrm{~mm}$

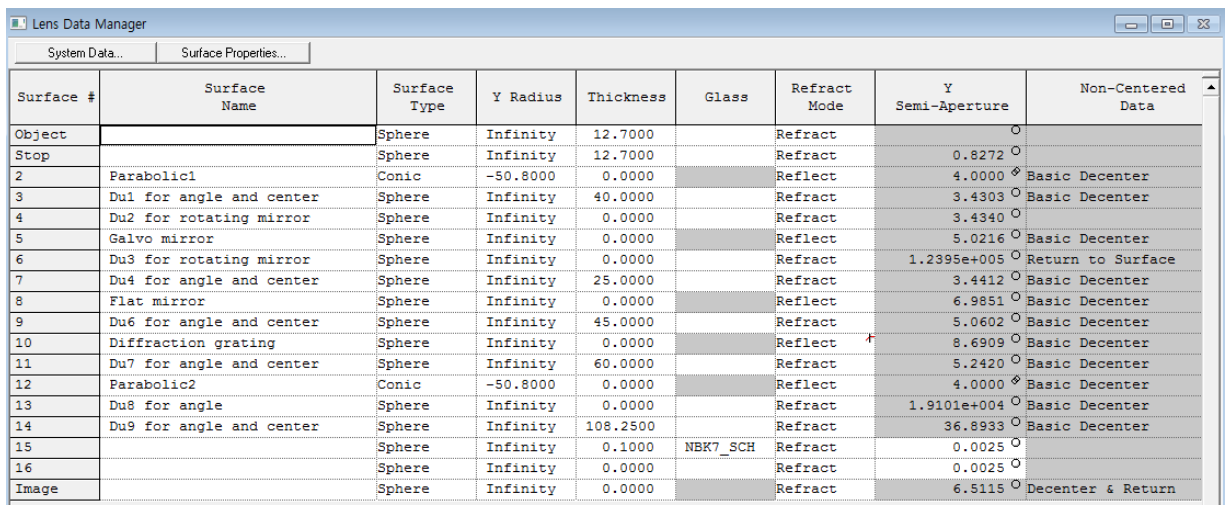

Figure 4. Example of one student submission. (Top left) Table listing a comparison of design requirements and system performance (Top right) Rays falling on the focal plane of the system at 1000.00 and $1000.25 \mathrm{~nm}$ prove a resolution capability better than $0.25 \mu \mathrm{m}$ with a $5 \mu \mathrm{m}$ exit slit. (Middle) 2D layout of the optical spectrum analyzer with key components identified. Rays are sketched for a 950, 1000, and $1050 \mathrm{~nm}$ and shown for three different positions of the scanning galvo mirror. (Bottom) Optical design prescription using commercial-off-the-shelf parts. 


\section{DESIGN PROJECT 3 - DESIGN FOR MANUFACTURABILITY / TOLERANCING}

Figure 5 depicts the third project: lens system evaluation using tolerance grade mapping. This project is based on the tolerance grade mapping approach by Herman et. al [6], and serves as an excellent starting point for teaching tolerancing methods and concepts related to design for manufacturability. This project differs from the previous two in the sense that students are not designing a new lens, but rather analyzing three existing lens designs in order to compare nominal performance to ease of manufacture. The students are given three designs - a Petzval lens, an inverse telephoto lens, and a Heliar lens (see Figure 6); all are F/2.8 with a $25 \mathrm{~mm}$ effective focal length and operate with a $\pm 10^{\circ}$ field-of-view. In the first part of the project, the students are tasked with analyzing the lens to assess nominal performance (RMS wavefront error) and then performing an inverse sensitivity analysis on each design in order to grade the tolerances which lead to a 0.05 wave degradation of RMS wavefront error. In the second part, the students perform a Monte Carlo tolerance analysis of the Petzval lens.

\section{Project 3 - Lens System Evaluation Using Tolerance Grade Mapping}

You have been tasked with selecting a lens system for manufacturing. You will be analyzing three lens designs (prescriptions on the next few pages) with respect to their manufacturability by performing a tolerance analysis on each. The lenses are all $F / 2.8$ with a $25 \mathrm{~mm}$ effective focal length and $\pm 10^{\circ} \mathrm{FOV}$. You will use the tolerance grade mapping approach that we discussed in class.

\begin{tabular}{|c|c|c|c|c|c|c|c|c|c|}
\hline & & & & $\begin{array}{l}\text { Standard } \\
\text { Process }\end{array}$ & & $\begin{array}{l}\text { Precision } \\
\text { Process }\end{array}$ & & $\begin{array}{c}\text { Ultra } \\
\text { Precision } \\
\text { Process }\end{array}$ & \\
\hline \multirow{2}{*}{$\begin{array}{c}\text { Surface } \\
\text { Tolerances }\end{array}$} & Power & (fringes) & \multirow{8}{*}{ 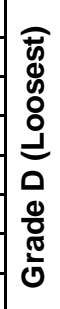 } & 5 & \multirow{8}{*}{$\begin{array}{l}0 \\
\frac{0}{0} \\
\frac{\pi}{2} \\
0\end{array}$} & 3 & \multirow{8}{*}{$\begin{array}{l}m \\
\frac{1}{0} \\
\frac{\pi}{0} \\
\text { U }\end{array}$} & 1 & \multirow{8}{*}{ 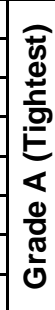 } \\
\hline & Irregularity & (fringes) & & 2 & & 0.5 & & 0.2 & \\
\hline \multirow{4}{*}{$\begin{array}{l}\text { Entire Lens } \\
\text { Tolerances }\end{array}$} & Wedge & $(\mathrm{mm})$ & & 0.05 & & 0.01 & & 0.005 & \\
\hline & Center Thickness & $(\mathrm{mm})$ & & 0.15 & & 0.05 & & 0.025 & \\
\hline & Index & - & & 0.001 & & 0.0005 & & 0.0002 & \\
\hline & $\mathrm{V} / \#$ & $(\%)$ & & 0.8 & & 0.5 & & 0.3 & \\
\hline \multirow{2}{*}{$\begin{array}{c}\text { Mounted Element } \\
\text { Tolerances }\end{array}$} & Tilt & (deg) & & 0.91 & & 0.18 & & 0.036 & \\
\hline & Decenter & $(\mathrm{mm})$ & & 0.13 & & 0.05 & & 0.01 & \\
\hline
\end{tabular}

- What is the nominal RMS wavefront error performance for the three lenses at $\mathrm{H}=0,0.7$, and 1.0 ?

- Based on the nominal performance, which design is 'best'?

- Based on the results of an inverse sensitivity analysis for a 0.05 wave degradation in RMS wavefront error, which design is 'best'? (Hint: Using the tolerance grade mapping approach, devise a method of conveying the results data graphically).

Now consider just the Petzval lens layout. All off the lenses are fabricated and mounted at the precision process level. Perform a Monte Carlo tolerance analysis, and be prepared to answer questions including the following:

- What manufacturing yield would you expect for an RMS wavefront error degradation of 0.05 waves off nominal?

- What allowable RMS wavefront error degradation would be required to maintain $>90 \%$ manufacturing yield?

- If the maximum allowable RMS wavefront error at any field is 0.4 waves, what would the manufacturing yield be?

Figure 5. Lens system evaluation using tolerance grade mapping project assignment. 

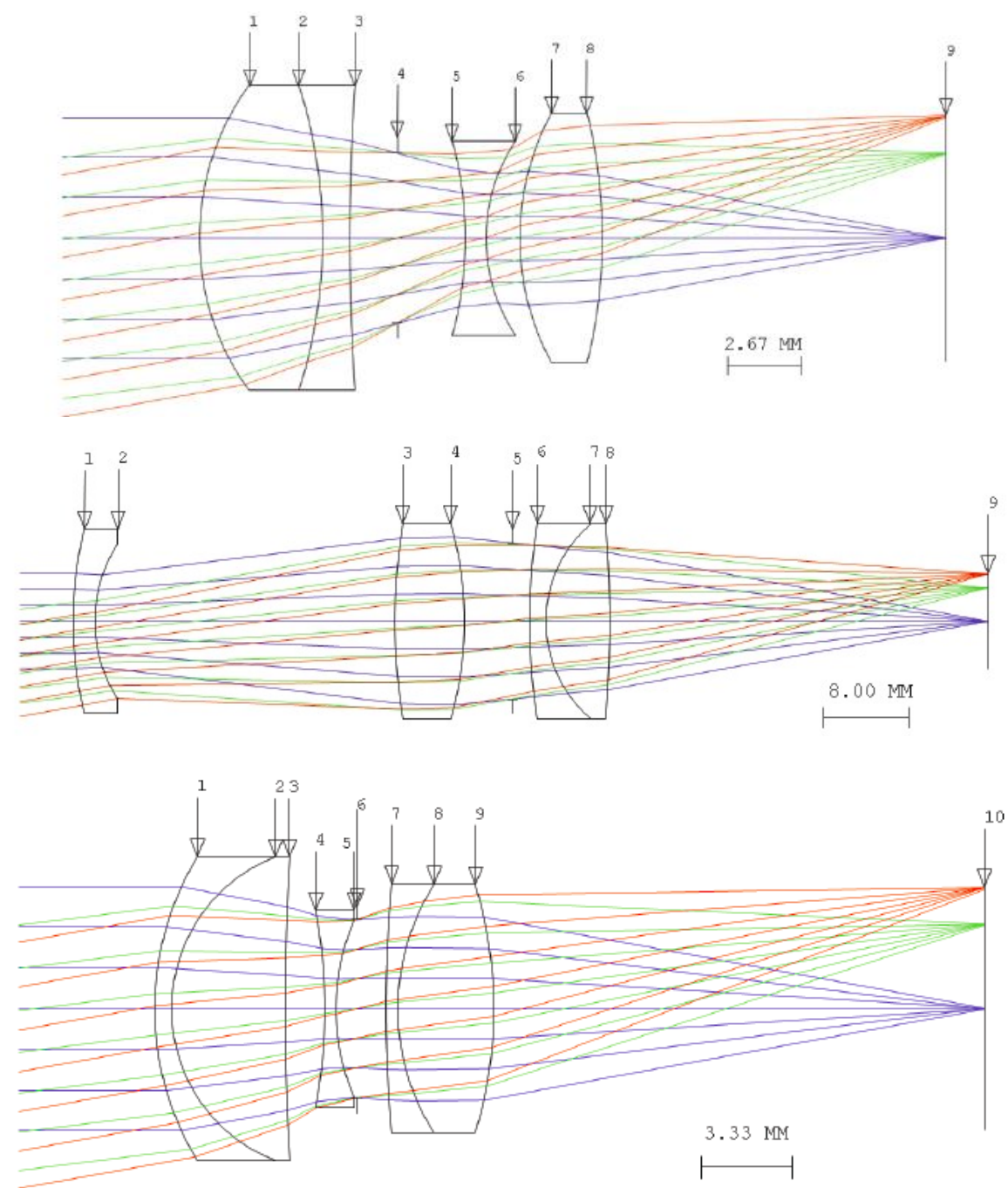

Figure 6. The three lens designs provided for the tolerance grade mapping project. (Top) Petzval lens taken from Laikin [5] and optimized in [6]. (Middle) Inverse telephoto lens taken from Laikin [5] and optimized in [6]. (Bottom) Heliar lens taken from Smith [2] and optimized in [6].

Figure 7 depicts some results from one student submission. The student found that that Heliar lens had the best nominal RMS wavefront error (0.02 waves), but the inverse telephoto had overall looser manufacturing requirements for a 0.05 wave degradation. The inverse telephoto lens was shown to have no components requiring a Grade A precision level and more than $70 \%$ of the specifications could be achieved with standard process precision levels. The student found that Heliar lens was the most difficult to manufacture. This result, however, does not agree with results published in [6] (in fact, no student was able to reproduce the results reported for these three lenses in [6]). The origin of this discrepancy has not yet been determined. 


\begin{tabular}{|c|c|c|c|}
\hline \multirow{2}{*}{$\begin{array}{c}\text { Normalized } \\
\text { Field }\end{array}$} & \multicolumn{3}{|c|}{ Nominal RMS wavefront error (waves) } \\
\cline { 2 - 4 } & Petzval & Inverse telephoto & Heliar \\
\hline 0.0 & 0.24 & 0.30 & 0.16 \\
\hline 0.7 & 0.31 & 0.20 & 0.18 \\
\hline 1.0 & 0.39 & 0.39 & 0.26 \\
\hline Mean & 0.32 & 0.30 & $\mathbf{0 . 2 0}$ \\
\hline
\end{tabular}
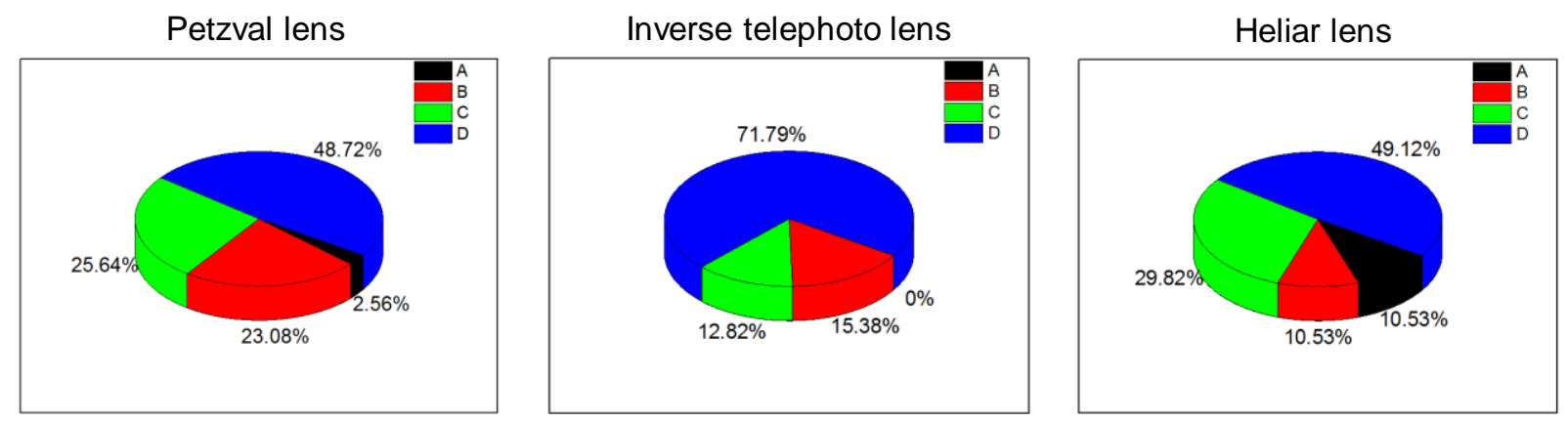

Figure 7. Example of one students submission. (Top) Evaluation of the nominal system performance (RMS wavefront error) shows the Heliar lens has the best performance. (Bottom) Results of the inverse sensitivity analysis and tolerance grade mapping for a 0.05 wave degradation in RMS wavefront error. the inverse teleophoto lens is found to have the loosest overall manufacturing specifications, with no tolerances

\section{CONCLUSION}

Three design projects have been incorporated into the Optical System Design course, which is part of the B.S. Optical Engineering degree program at Rose-Hulman Institute of Technology. The first project is the design of a fast photographic zoom lens. Constraints are provided for sensor format, overall length, allowable glasses, maximum number of elements, maximum distortion, and the required image quality. In the second design project, students are tasked with the design of a reflective spectrometer system utilizing off-the-shelf optics from a provided list. Design specifications are placed on the wavelength span, resolution bandwidth, input format, and module footprint. The third design project places students in the position of selecting the best design for manufacture based on the results of an inverse sensitivity analysis and Monte Carlo tolerance analysis. The results are weighed against the expected manufacturing cost. This paper details the implementation of these projects. Anecdotally, students who successfully complete all three projects demonstrate deeper understanding of lens design and several specific topics (optimization, multiconfiguration systems, coordinate breaks, diffractive optics, and tolerancing).

\section{REFERENCES}

[1] R. Kingslake and R. B. Johnson, Lens Design Fundamentals, 2nd ed. Burlington, MA: Academic Press, 2009.

[2] W. Smith, Modern Lens Design, 2nd ed. New York: McGraw-Hill, 2004.

[3] J. M. Geary, Introduction to Lens Design: With Practical Zemax Examples: Willmann-Bell, 2002.

[4] R. Fischer, B. Tadic-Galeb, and P. R. Yoder, Optical System Design, 2nd ed. New York: McGraw-Hill, 2008.

[5] M. Laikin, Lens Design, 4th ed. Boca Raton, FL: CRC Press, 2006.

[6] E. Herman, R. N. Youngworth, and J. Sasian, "Efficient assessment of lens manufacturability in optical design," Proc. of SPIE, vol. 9293, 2014. 